\title{
PROGRAM PEMBELAJARAN MADRASAH DINIYAH (MADIN) SEBAGAI SOLUSI UNTUK MENINGKATKAN PENGETAHUAN AGAMA BAGI SISWA SEKOLAH UMUM
}

\author{
Suhra Wardi \\ Fakultas Ushuludin Adab dan Dakwah IAIN Pontianak \\ Email: suhrawardi@gmail.com
}

\begin{abstract}
Human Resource Development is a key factor to achieve the progress of the country and nation. Creating quality human resources is not only in terms of intellectual intelligence, but more important is the religious intelligence. Religion teaches that there is damage on earth because of human actions. Achieving prosperity and peace for all mankind will be achieved and felt because of the balance of intellectual and religious intelligence, so that life peace is expected and avoid damage on earth. Pontianak City Government anticipates the realization of a balance of intellectual and religious intelligence through the establishment of the Madrasah Diniyah Takmiliyah program for public school students. The Pontianak City Government implements this program in collaboration with the Pontianak City Ministry of Religion and the Pontianak State Islamic Institute (IAIN). This policy was taken because of the lack of religious material for public school students in the national curriculum. Regional autonomy makes it possible for the Regional Head to stipulate Regional Regulations (Perda) related to strengthening religious education needed by the region in order to achieve the welfare of the community.
\end{abstract}

Keywords: Learning Madrasah Diniyah, Solution, and Increase Religious Knowledge

\section{PENDAHULUAN}

Visi Pemerintah Kota Pontianak “ Pontianak Kota Khatulistiwa berwawasan Lingkungan Terdepan Dalam Kualitas sumber Daya Manusia, Prima dalam Pelayanan Publik, Didukung Dengan Tata kelola Pemerintahan Yang baik Dan bersih". Visi ini secara umum sudah menampakkan hasilnya dengan adanya kemajuan -kemajuan yang di raih Pemerintah Kota Pontianak.

Walikota Pontianak periode 2014-2018 telah sukses memmimpin Kota Pontianak sehingga Pontianak mengalami kemajuan yang sangat signifikan. Semasa kepemimpinannya Walikota Sutarmidji telah memperoleh 250 Piagam Penghargaan baik di tingkat Provinsi, Nasional maupun Internasional, salah satu diantaranya adalah Leadership Award dari Menteri Dalam Negeri.

Angka IPM terakhir yang dirilis BPS adalah IPM tahun 2017. IPM Kota Pontianak pada tahun 2017 mencapai angka 77,93. Angka IPM ini jauh meningkat dibanding capaian tahun 2013 yang baru mencapai angka 75,98 . Peningkatan IPM ini di dorong oleh upaya peningkatan kualitas bidang kesehatan dan bidang pendidikan serta terjaganya kondisi makro ekonomi yang mempengaruhi daya beli masyarakat.Dengan kondisi IPM Kota Pontianak yang selalu naik dari tahun ke tahun, dapat diartikan bahwa Pembangunan Manusia di Kota Pontianak cenderung semakin baik, khususnya selama 5 tahun terakhir. IPM di bentuk oleh 3 dimensi dasar yaitu umur panjang, hidup sehat.

Secara garis besar kinerja pembangunan di bidang pendidikan menunjukkan kinerja yang baik. Hal ini tercermin dari capaian beberapa indikator bidang pendidikan yang menunjukkan peningkatan. Pada tahun 2017 Angka Partisipasi Kasar (APK) SD mencapai 127,77\%, APK SLTP mencapai 114,82 dan APK SLTA mencapai 101,14\%. Sedangkan Angka Partisipasi Murni (APM) SD mencapai 107,06\%, APM SLTP mencapai 104,19\%, sedangkan APM SLTA mencapai 94,10\%. 
Indikator Pendidikan lainnya juga menunjukkan perkembangan yang menggembirakan seperti angka putus sekolah SLTP sebesar $0,11 \%$ dan angka putus sekolah SLTA sebesar $0,19 \%$.

Data IPM dan APM memang menunjukkan hasil yang memuaskan, namun dalam kenyataan tidak dapat kita pungkiri bahwa masih kita temukan adanya penyimpangan perilaku siswa. Siswa yang terlibat dalam tawuran, kenakalan remaja, pergaulan bebas yang melanggar norma agama bahkan ada yang terlibat obat-obat terlarang. Karakter pelajar yang buruk seperti itu menjadi tanggungjawab orang tua, pemerintah dan masyarakat. Salah satu strategi untuk menanggulanginya adalah melalui penguatan pendidikan agama. Agama diharapkan menjadi benteng utama para pelajar untuk menjaga diri mereka masing-masing agar tidak terjebak pada perilaku yang menyimpang.

Program Madrasah Diniyah bagi siswa sekolah umum dapat diterapkan guna memperkuat pengetahuan agama. Selama ini siswa sekolah umum sangat minim memperoleh materi agama. Kurikulum Nasional hanya mengalokasikan 2 (dua) jam pelajaran agama per minggu, itupun penyajiannya banyak pada teori belaka.

Melalui tulisan ini ingin di sampaikan bagaimana program Madrasah Diniyah bagi siswa sekolah umum akan dapat membantu memperkuat pengetahuan agama peserta didik. Tulisan ini juga mengungkapkan bahwa Pemerintah Kota Pontianak telah mengimplementasikan program Madrasah Diniyah untuk siswa sekolah umum melalui beberapa masjid di Kota Pontianak. Terakhir melalui tulisan ini, ingin diungkapkan bagaimana secara teknis program Madrasah Diniyah ini dapat dilaksanakan bagi siswa sekolah umum, sehingga diharapkan akan terbentuk karakter akhlak mulia pada siswa sekolah umum untuk mewujudkan sumber daya manusia Indonesia yang berkualitas.

\section{METODE PENELITIAN}

Lokasi penelitian ini dilaksanakan di sekolah umum kota pontianak. Fokus dalam penelitian ini adalah program pembelajaran madrasah diniyah (madin) sebagai solusi untuk meningkatkan pengetahuan agama bagi siswa sekolah umum.

Penelitian ini menggunakan metode kualitatif, yaitu permasalahan dibahas dengan mendiskripsikan,menguraikan dan memaparkan kondisi nyata yang didukung oleh data-data tertulis maupun data-data hasil wawancara. Metode pengumpulan data menggunakan metode observasi, wawancara,dan dokumentasi.

Sumber data penelitianini dibagi menjadi dua yaitu data primer dan data sekunder. Data primer merupakan data yang diperoleh atau dikumpulkan langsung dilapangan dari informan.Informan dalam penelitian ini adalah kementrian agama, kepala sekoah, komite sekolah dan orang tua murid. Data sekunder yaitu data yang diperoleh secara tidak langsung dari sumbernya. Data sekunder penelitian ini yaitu program kerja, daftar absensi, Presensi kegiatan, dan data pendukung lainnya. Pemeriksaan keabsahan data menggunakan metode triangulasi sumber.

Penulis menganalisis data yang terkumpul baik dari hasil wawancara, observasi serta dokumentasi menggunakan metode kualitatif analisis yang terdiri dari beberapa tahap yaitu: (1) Pengumpulan data; (2) reduksi data; (3) penyajian data; dan (4) penarikan kesimpulan atau verifikasi data.

\section{HASIL DAN PEMBAHASAN}

Pemerintah Kota Pontianak dalam melaksanakan pembangunan sumber daya manusia yang berkualitas telah membangun gedung -gedung sekolah yang representatif dan melengkapinya dengan sarana prasarana yang baik. Secara fisik hampir $90 \%$ bangunan gedung sekolah-sekolah sudah bagus dan mencukupi daya tampung siswa Kota Pontianak. Di sisi lain , Pemerintah Kota Pontianak mengharapkan agar Kota Pontianak menjadi Kota religius. Beberapa program rutin telah dilaksanakan untuk mendukung terwujudnya kota religius, antara lain: Program Khataman Al Qur'an Massal se-Kota Pontianak yang diselenggarakan setiap tahun di bulan oktober yang bertepatan dengan rangkaian perayaan Hari Jadi Kota Pontianak. Pada Tahun 2018 peserta acara Khataman Al Qur'an massal berjumlah 23.000 peserta sehingga mendapatkan Rekor Muri sebagai 
peserta terbanyak se Indonesia, Pawai Ta'ruf se Kota Pontianak menyambut bulan Suci Ramadhan dan Tahun Baru Hijriyah 1 Muharram. Pemerintah Kota Pontianak juga menetapkan bahwa siswa lulusan Sekolah Dasar(SD) wajib sudah bisa membaca Al Qur'an, lulusan SMP wajib sudah Khatam Al Qur'an dan siswa lulusan SMA/SMK wajib hafal surah-surah pendek Al Qur'an. Sementara itu masih diketemukan adanya perilaku yang menyimpang dari sebagian siswa yang melanggar norma-norma dan aturanaturan agama. Derasnya pengaruh negatif/godaan teknologi informatika yang disalah gunakan telah menjerumuskan siswa ke hal-hal negatif.

Selain itu ada beberapa Permasalahan yang penting untuk di waspadai: (1) Adanya aliran - aliran sesat dimasyarakat yang dapat mengancam para pelajar Kota Pontianak ikutikutan aliran sesat tersebut, disebabkan mereka belum mampu membaca dan memahami isi Kandungan Al-Qur'an dengan baik; (2) Pengaruh lingkungan yang tidak kondusif menyebabkan perilaku menyimpang pada para pelajar; (3) Kurangnya Pengetahuan Agama Islam bagi siswaPendidikan Formal atau umum baik di tingkat dasar dan menengah.

Penulis menganalisa bahwa mata pelajaran agama di sekolah umum yang hanya 2(dua) jam per minggu tidaklan cukup untuk memenuhi kebutuhan siswa akan materi agama. Jumlah 2 jam pelajaran itu pun lebih banyak materi teori. Sementara ilmu agama tidak hanya sekedar teori belaka, tapi yang lebih penting adalah implementasi dari kaidahkaidah agama. Siswa butuh memahami konsep-konsep agama, tetapi yang lebih penting adalah memperaktekkan ajaran agama supaya tumbuh karakter yang sehat dan berakhlak mulia. Keberhasilan pondok-pondok Pesantren dalam membentuk karakter yang sehat dan berakhlak mulia pada para santrinya adalah karena muatan materi agamanya cukup memadai dan di peraktekkan dalam kehidupan santri sehari-hari.

Berangkat dari pemikiran pentingnya tambahan materi agama dan di peraktekkan dalam kehidupan sehari-hari maka Pemerintah Kota Pontianak pada tahun 2017 melalui kerjasama dengan Kementerian Agama Kota Pontianak telah membentuk program Madrasah
Diniyah Takmiiyah bagi siswa sekolah umum di Masjid-masjid . Program madin ini di dukung dengan dana APBD Kota Pontianak.

Pemerintah Kota Pontianak melalui kerja sama denga Kementerian Agama Kota Pontianak pada tahun 2017 telah membentuk Program Madrasah Diniyah Takmiliyah bagi siswa sekolah umum di enam masjid di enam kecamatan diantaranya: (1) Kec. Ptk Kota : Masjid As-Sirath, Jl.Suwigyo; (2) Kec. Ptk Selatan : Masjid Nurul Wahdah, Jl. Media; (3) Kec. Ptk Barat : Masjid Sirajul Munir, Kom Yos Sudarso; (4) Kec. Ptk Utara : Masjid Jami At Taqwa.Jl.Gst.Situt; (5) Kec. Ptk Tenggara:Masjid Nurul Huda Jl Perdana; (6) Kec. Ptk Timur : Masjid Nurul Salam, Jl.Ya'M.Sabran. Adapun dasar Penyelenggaraan Madrasah Diniyah Takmiliyah berdasarkan pada: (1) UndangUndang No.20 Tahun 2003 Tentang Sistem; (2) Pendidikan Nasional; (3) Peraturan Pemerintah No.55 tahun 2007 tentang Pendidikan; (4) Agama dan Pendidikan Keagamaan; (5) Peraturan Pemerintah No.73 Tahun 1991 Tentang Pendidikan Luar Sekolah; (6) SK.Walikota Pontianak No.202/ORG/2016.Tentang Inovasi Pemkot PontianakKurikulum Madrasah Diniyah Takmiliyah (MDT) disusun sesuai dengan jenjang pendidikan . Kurikulum Madrasah Diniyah Takmiliyah (MDT) disusun sesuai dengan jenjang pendidikan yaitu : (1) Kurikulum MDT Awaliyah (SD) ditempuh dalam 4 (empat) tahun masa belajar dengan 18 jam pelajaran perminggu; (2) Kurikulum MDT Wustha (SMP) ditempuh dalam 2 (dua) tahun masa belajar dengan 18 jam pelajaran perminggu; (3) Kurikulum MDT Ulya (SMA) ditempuh dalam 2 (dua) tahun masa belajar dengan 18 jam pelajaran perminggu.

Kementerian Agama Melalui Dirjen Pendis telah mengeluarkan kebijakan berkaitan dengan Kurikulum yaitu : (1) Kurikulum sesuai karakteristik MDT dan semangat PP No. 19 Tahun 2005 Tentang Standar Nasional Pendidikan, maka model pengembangan kurikulum dan silabusnya bersifat desentralistik. Pengembangan kurikulum harus mengacu pada Standar Isi dan Standar; (2) Kompetensi Lulusan yang sudah ditetapkan oleh Dirjen Pendis Kemenag RI; (3) Struktur kurikulum MDT paling sedikit meliputi mata pelajaran; (4) Alqur'an, Hadits, Aqidah, 
Akhlaq, Fiqih, SKI dan Bahasa Arab; (4) Pemerintah berperan mengarahkan dan memfasilitasi terhadap upaya pengembangan kurikulum yang dilakukan oleh guru, komite, orang tua/wali santri serta para stakeholder lainnya; (5) Satuan ajar dan buku ajar dapat dikembangkan oleh satuan pendidikan dengan mempertimbangkan kompetensi dan muatan lokal masing-masing; (6) Pemerintah menjamin kemandirian kurikulum MDT yang bervariasi sesuai orientasi dan misi dakwah pengelola dan keragaman sumber belajarnya.

Ketentuan Alokasi Waktu: (1) MDTA Kelas I adalah 30 menit; (2) MDTA Kelas II s/d IV adalah 40 menit; (3) MDTW Kelas I s/d II adalah 45 menit; (4) MDTU Kleas I s/d II adalah 45 menit .

Tabel 1. Struktur Kuriulum Mata Pelajaran Madrasah Diniyah Takmiliyah Awwaliyah, Wustho dan Ulya

\section{No Mata Pelajaran}

\section{Mutu MDTW MDTU}

\begin{tabular}{llcccccccc}
\cline { 3 - 8 } & & I & II & III & IV & I & II & I & II \\
\hline $\mathbf{1}$ & Al-qur'an & 5 & 5 & 4 & 4 & 3 & 3 & 2 & 2 \\
\hline $\mathbf{2}$ & Hadist & 1 & 1 & 2 & 2 & 2 & 2 & 2 & 25 \\
\hline $\mathbf{3}$ & Aqiqah & 1 & 1 & 1 & 1 & 1 & 1 & 2 & 2 \\
\hline $\mathbf{4}$ & Ahlaq & 2 & 2 & 2 & 2 & 2 & 2 & 2 & 2 \\
\hline $\mathbf{5}$ & Fiqih & 4 & 4 & 4 & 4 & 4 & 4 & 4 & 4 \\
\hline $\mathbf{6}$ & Tarbih Islam & 1 & 1 & 1 & 1 & 2 & 2 & 2 & 2 \\
\hline $\mathbf{7}$ & Bahasa Arab & 4 & 4 & 4 & 4 & 4 & 4 & 4 & 4 \\
$\mathbf{8}$ & Muatan Lokal & - & - & - & - & - & - & - & -
\end{tabular}

a. Arab pegon

b. Emmla

c. dll

$\begin{array}{lllllllll}\text { Jumlah } & 18 & 18 & 18 & 18 & 18 & 18 & 18 & 18\end{array}$

Adapun program pengembangan diri dan pembiasaan akhlaqul karimah diberikan melalui kegiatan-kegiatan yang mengakomodasi minat, bakat dan potensi santri serta, penciptaan lingkungan religius di Madrasah Diniyah Takmiliyah. Program ini dijalankan dengan menyesuaikan kondisi lingkungan MDT di luar pembelajaran kelas.

Pola Pembelajaran di Pesantren: Bandungan (bandongan atau wetonan)

Bandungan atau wetonan berarti "memperhatikan secara seksama atau menyimak". Dalam sistem pendidikan modern bandungan disebut pula dengan sistem kolektif (collection learning atau together learning). Sistem bandungan adalah sistem transfer keilmuan atau proses belajar mengajar, dimana sekelompok santri mendengarkan seorang guru yang membaca, menerjemahkan dan menerangkan buku-buku Islam dalam bahasa Arab. Kelompok kelas dari sistem bandongan ini disebut halaqah yang artinya sekelompok santri yang belajar di bawah bimbingan seorang guru. 


\section{Sorogan}

Sorogan adalah sistem belajar secara individual, atau seorang santri nyorog (menghadap guru sendiri-sendiri) untuk dibacakan (diajarkan) oleh gurunya beberapa bagian dari materi yang dipelajarinya, kemudian sang santri menirukannya berulang kali. Dengan sistem sorogan, setiap santri mendapat kesempatan untuk belajar secara langsung dari gurunya.

\section{Bahtsul Masa'il}

Bahtsul Masa'il pada awalnya merupakan forum para ulama-kyai untuk membahas masalah-masalah keagamaan yang terjadi secara riil dalam kehidupan masyarakat (waqi'iyyah) dengan tujuan untuk mengetahui status hukum fiqihnya. Dalam perkembangannya Bahtsul Masa'il tidak lagi menjadi forum ulama tetapi juga diterapkan dikalangan santri.

Kegiatan ekstrakurikuler merupakan kegiatan di luar mata pelajaran tetapi merupakan bagian integral dari kurikulum Madrasah Diniyah Takmiliyah. Pemilihan kegiatan ekstrakurikuler disesuaikan dengan kondisi dan kemampuan Madrasah tersebut. Tujuan khusus kegiatan ektrakurikuler adalah untuk menunjang pendidikan santri dalam mengembangkan bakat, minat kreativitas, komptensi dan kebiasaan dalam kehidupan, kemampuan kehidupan beragama, kemampuan sosial, kemampuan belajar, wawasan, kemampuan memecahkan masalah dan kemandirian. Ekstrakurikuler yang bisa diterapkan di Madrasah Diniyah Takmiliyah, antara lain: (1) Seni Tilawah/Qiro'ah; (2) Pembacaan Tahlil, Barzanji/Diba'an, Istighotsah; (3) Mudadlarah/ Khitabah/ Latihan Ceramah; (4) Forum Debat; (5) Imla'/Dikte/Menulis Arab (6) Khath/Seni Kaligrafi; (7) Praktik Perawatan Jenazah (Tajhizul Mayit); (8) Pembinaan dan Pengembangan Kesenian Islami; (9) Olahraga dan Beladiri; (10) Pramuka Santri.

Model Kegiatan Pembiasaan Akhlaq Karimah, dapat diterapkan menggunakan strategi sebagai berikut: (1) Penggunaan pendekatan system; (2) Penciptaan komitmen bersama; (3) Pengelolahan dengan program yang jelas; (4) Perbaikan berkesinambungan . Beberapa kegiatan pembiasaan yang bisa dikembangkan antara lain : Pembiasaan Shalat
Berjama'ah, Sholat Sunnah, Puasa Sunnah, Baca Qur'an dan do'a sebelum dan sesudah pelajaran madrasah, Tahlil dan Barzanji, Penegakkan kedisiplinan, Cium tangan sebagai penghormatan kepada guru, Latihan hidup prihatin dan kesederhanaan, Menjalani hidup penuh kemandirian, Pembiasaan Dzikir dan Wirid, Berpakaian Sopan dan Islami.

Secara teknis program Madrasah Diniyah Takmiliyah ini dapat dilaksanakan bagi siswa sekolah umum, sehingga diharapkan akan terbentuk karakter akhlak mulia pada siswa sekolah umum untuk mewujudkan sumber daya manusia Indonesia yang berkualitas.

Proses pembelajaran Madrasah Diniyah Takmiliyah yang di laksanakan di masjidmasjid waktunya fleksibel. Jika siswa belajar di sekolah umum pagi hari maka waktu pembelajran di masjid dapat dilakukan sore lepas sholat Ashar atau malam selepas sholat Maghrib. Sebaliknya jika siswa sekolah umum belajar di sekolah pada sore hari maka mereka dapat belajar Madrasah Diniyah Takmiliyah pada pagi hari, setelah sholat subuh atau setelah sholat dhuha. Kesepakatan di lakukan antara siswa dengan ustad /gurunya

Program Madrasah Diniyah Takmiliyah ini dapat juga diselenggarakan di sekolahsekolah dengan menyesuaikan kondisi sekolah masing-masing. Kepala sekolah melalui Komite Sekolah dan orang tua murid dapat bermusyawarah secara terbuka dan transparan untuk penyelenggaraannya.

\section{SIMPULAN DAN SARAN \\ Simpulan}

Program pendidikan Madrasah Diniyah Takmiliyah merupakan solusi terhadap kurangnya pemahaman materi agama yang dimiliki oleh siswa sekolah umum. Model pembelajaran yang sederhana di masjid-masjid atau di sekolah -sekolah seusai pelajaran umum kurikulum nasional diberikan pada siswa. Program Madrasah Diniyah Takmiliyah ini diharapkan mampu mengurangi perilaku menyimpang siswa sekolah umum. Pengetahuan agama yang memadai akan menjadi ketahanan jati diri siswa sekolah umum untuk menghadapi berbagai tantangan dan ancaman kehidupan moderen yang serba instan dan banyaknya pengaruh negatif pada kehidupan para remaja. 
Saran

Pemerintah Daerah dapat menetapkan program Madrasah Diniyah Takmiliyah ini menjadi program pendidikan yang berlaku di daerah masing-masing melalui penetapan Peraturan Daerah (Perda). Otonomi Daerah memungkinkan bagi kepala daerah untuk mengambil kebijakan ini dengan harapan terwujudnya nuansa kehidupan relijius di daerah dan mengantisipasi terjadinya penyimpangan perilaku siswa.

\section{DAFTAR PUSTAKA}

Bappeda Kota Pontianak. 2018. Rancangan Peraturan Daerah Tentang Rencana Pembangunan Jangka Menengah Daerah (RPJMD) Kota Pontianak Tahun 20202024. Pontianak: Bappeda Kota Pontianak.

2014-2018. Pontianak: Pemerintah Kota Pontianak.

Direktorat Pendidikan Diniyah Dan Pondok Pesantren Direktorat Pendidikan Islam Kementerian Agama RI.2013. Pedoman Standar Pelayanan Minimal Madrasah Diniyah Takmiliyah.

Direktorat Pendidikan Diniyah Dan Pondok Pesantren Direktorat Pendidikan Islam
Kementerian Agama RI.2015.

Pengembangan Kurikulum Madrasah Diniyah Takmiliyah.

Direktorat Pendidikan Diniyah Dan Pondok Pesantren Direktorat Pendidikan Islam Kementerian Agama RI.2015. Pengembangan Model Pembelajaran Madrasah Diniyah Takmiliyah

Direktorat Pendidikan Diniyah Dan Pondok Pesantren Direktorat Pendidikan Islam Kementerian Agama RI.2015. Panduan Penyelenggaraan Madrasah Diniyah Takmiliyah.

Direktorat Pendidikan Diniyah Dan Pondok Pesantren Direktorat Pendidikan Islam Kementerian Agama RI.2015. Standar Kelulusan dan Standar isi Mapel PAI dan Bahasa Arab Madrasah Diniyah Takmiliyah.

Pemerintah Kota Pontianak. 2018. Laporan Kinerja 2017. Pontianak: Pemerintah Kota Pontianak.

Pemerintah Kota Pontianak. 2018. Laporan Keterangan Pertanggungjawaban Akhir Masa Jabatan Walikota Pontianak Tahun 